\title{
Para além do eurocentrismo: reconstruindo a teoria das greves
}

\section{Beyond eurocentrism: rebuilding the theory of strikes}

\section{Ruy Gomes Braga* Alexandre Guelerman ${ }^{*}$}

Resenha: NOWAK, Jörg. Mass Strikes and Social Movements in Brazil and India: Popular Mobilisation in the Long Depression. Nova lorque: Springer, 2019.

Palavras-chave: sindicalismo, classe trabalhadora, Sul global.

Keywords: Unionism, Working class, Global South.

N as três primeiras décadas que se seguiram ao pós-Segunda Guerra, os estudos acadêmicos sobre sindicalismo no Norte global foram usualmente dominados pela perspectiva da "Teoria das Relações Industriais", um estilo de abordagem das relações trabalhistas muito influente mundo afora, inclusive no Brasil. Este paradigma, em sua formulação original, postulava uma tendência unívoca de "institucionalização do conflito trabalhista", envolvendo a formação de sindicatos burocráticos reconhecidos como atores legítimos pelos empresários e pelo Estado. Esse reconhecimento era acompanhado por uma pauta normalmente focada nas melhorias nos locais de trabalho e nos aumentos salariais por meio de negociações coletivas estáveis o suficiente a fim de evitar ao máximo formas de agitação operária radicais, como greves, por exemplo.

O controle do direito de greves era de responsabilidade tanto do Estado quanto dos sindicatos que, após a celebração do acordo coletivo, transformava-se em um verdadeiro "fiscal do contrato". Quando aconteciam, as greves ficavam sempre restritas a pautas dos

* Doutor em Ciências Sociais pela Universidade Estadual de Campinas (Unicamp). Professor Titular do Departamento de Sociologia da Universidade de São Paulo (USP). E-mail: ruy.braga@usp.br. ORCID: https:// orcid.org/0000-0002-8512-4306.

** Bacharel em Ciências Sociais pela Universidade de São Paulo (USP). Mestrando do Programa de Pós-Graduação em Sociologia da Universidade de São Paulo (USP). E-mail: alexandre_egramos@usp.br. ORCID: https://orcid.org/0000-0002-8674-2907. 
locais de trabalho, marginalizando iniciativas "espontâneas" ou pautas mais amplas. Nesse quadro interpretativo, as particularidades do movimento grevista no Sul global eram tidas como verdadeiros desvios associados ao subdesenvolvimento das sociedades nacionais ou à influência de partidos populistas imersos na retórica anti-imperialista.

O conjunto de reestruturações do capitalismo nas últimas quatro décadas abalou o compromisso de classe fordista no Norte global, erodindo a suposta universalidade do modelo. Esse movimento rumo à desconstrução das formas reguladas das relações de trabalho lançou um novo desafio para os estudiosos do trabalho. Cada dia foi se tornando mais claro que a abordagem em termos de relações industriais ao estilo estadunidense espelhou a excepcionalidade de um padrão histórico de agitação trabalhista cujo sentido não é mais capaz de revelar as tendências dominantes no atual contexto globalizado. A partir de uma abordagem multidisciplinar e internacional, e dialogando com importantes formulações como as teorias dos movimentos sociais e os debates neomarxistas em torno das classes sociais, os chamados "estudos do trabalho global" propuseram uma ampla reconfiguração da análise das agitações trabalhistas. Essa renovação, mais saliente a partir dos anos 1980, propôs superar os limites do padrão fordista de agitação trabalhista a partir da ampliação dos estudos rumo às formas de ação, consciência, experiência e organização que transcendem a organização sindical formal; às formas de atuação política das massas empobrecidas urbanas no Sul global; ao papel da imigração dos trabalhadores; ao papel das divisões de gênero e das divisões étnicas; às coalizões entre sindicatos e novos movimentos sociais urbanos; às formas de agitação trabalhista transnacionais; e aos impactos das transformações técnicas e espaciais nas cadeias produtivas globais.

Publicada em março de 2019, a mais recente obra de Jörg Nowak - Mass Strikes and Social Movements in Brazil and India: Popular mobilisation in the long depression - representa um momento muito especial da evolução desse campo investigativo. O livro é permeado pelo impulso de renovação teórica do campo, tendo em vista dois vetores principais: o desafio ao eurocentrismo e o trânsito por diferentes fronteiras disciplinares. Nesse sentido, cumpre ressaltar, antes de mais nada, a riqueza do levantamento bibliográfico que subsidia sua construção teórica.

No capítulo 2, o autor analisa dezenas de autores, combinando historiadores, geógrafos e sociólogos; começa expondo as atualizações contemporâneas no debate acadêmico acerca da classe trabalhadora, para em seguida descrever os principais pontos da trajetória de crise do paradigma clássico das relações industriais, e finalmente analisar aquelas formulações que buscaram enquadrar analiticamente novos atores e novas dinâmicas no estudo das agitações trabalhistas.

No capítulo 3, o autor desloca-se para o âmbito da economia política, onde começa por situar os principais debates contemporâneos acerca das transformações na economia mundial, salientando o avanço da informalidade e da precariedade laboral nos marcos de 
uma nova divisão internacional do trabalho entre o Norte e o Sul globais, para, em seguida, voltar-se para o estudo minucioso dos ciclos econômicos, sintetizando os impactos da atual depressão econômica sobre as economias emergentes, além de discutir formulações teóricas acerca das ondas longas da economia mundial em conexão com os movimentos de agitação trabalhista.

A despeito desses capítulos notáveis e provocantes, a nosso ver, a principal virtude do livro consiste em reconstruir a teoria da greve de massas originalmente elaborada por Rosa Luxemburgo, a fim de interpretar o padrão emergente de agitações trabalhistas no Sul global. No capítulo 2, quando Nowak analisa autores que criticaram a ênfase exclusiva dos estudos do trabalho nos sindicatos, Rosa Luxemburgo é a primeira autora discutida, e sua presença destoa dos demais autores presentes na seção. Essa opção de estruturação do argumento ressalta que os estudos do trabalho global não configuram um campo completamente "novo" de investigações. No entanto, a importância atribuída por Nowak à teoria da greve de massas revela como a obra da revolucionária polonesa pode ser recuperada de uma maneira inovadora, inspirando outras pesquisas nesse mesmo campo de estudos.

Afinal, a polêmica travada por essa autora, ainda nos primeiros anos do século $X X$, contra os dirigentes socialdemocratas alemães que pensavam nas greves de massa unicamente como fenômenos conduzidos por sindicatos, encontra uma certa "afinidade eletiva" com a crítica contemporânea ao paradigma clássico da teoria das relações industriais. A análise que essa autora faz da onda de greves na Rússia entre 1896 e 1906 revela a importância histórica de um caso em que as greves não são "programadas" pelas direções, mas emergem do acúmulo de contradições sociais, e sua dinâmica não é previamente calculada, mas contingentemente construída. Ademais, não se trata de um processo exclusivamente político, na medida em que se iniciou, a partir de 1896, com ondas de greves fragmentadas e puramente econômicas que, contudo, foram revelando para a classe trabalhadora russa a importância da organização política. Trata-se, como sabemos, de um processo cujo ápice foi a revolução de 1905. Iniciado por meio de uma greve geral de solidariedade ao operariado de São Petersburgo, esse processo difundiu-se rapidamente, desdobrando-se em incontáveis greves e protestos locais. Conforme a conflitualidade progredia, as greves "demonstrativas" tornavam-se secundárias, em favor das greves "de combate", que não definiam previamente sua duração. Por fim, a autora ressalta como nas greves de massa russas o protagonismo político não estava nas mãos dos operários organizados sindicalmente, mas dos grupos precários e desorganizados de trabalhadores que rapidamente criaram suas próprias organizações, impulsionando suas demandas específicas.

Partindo da análise luxemburguiana, o autor diferencia o conceito geral de "onda grevista" (diversas greves envolvendo grande número de trabalhadores em uma determinada região geográfica em um mesmo período) da especificidade das greves de massa, que

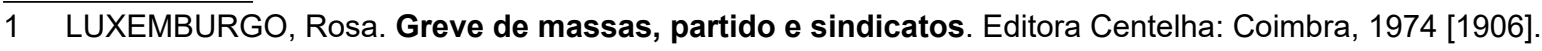


pressupõem a difusão do movimento paredista, seja por um ou mais centros coordenados, seja pelo simples reconhecimento de greves prévias alimentando greves posteriores em um efeito cascata. Fundamentais são também, para caracterizar dessa forma uma greve de massas, seu impacto sobre a vida política nacional e os saldos organizativos trazidos para o movimento dos trabalhadores. Além disso, as greves de massas tendem a combinar lutas ofensivas e defensivas, políticas e econômicas, de combate e demonstrativas, gerais e parciais, em um movimento que desafia tanto as empresas quanto o governo.

Essa pluralidade de formas de luta exige que se produzam tipologias distintas das ondas grevistas de massa. No que se refere à dinâmica organizativa da greve de massa, Nowak identifica três tipos: "greves de massa demonstrativas", "greves de massa de combate centralmente coordenadas" e "greves de massa de combate dirigidas pelos trabalhadores" nessas últimas, ainda que haja envolvimento de atores institucionalizados como sindicatos, esse envolvimento não é o fator central no processo de difusão das greves. No que se refere à dinâmica espacial das greves de massas, é possível identificar também três tipos: "greves setoriais imitadoras", "greves nacionais transetoriais" e "greves de massa regionais".

Contudo, mais importante do que essas tipologias é o enquadramento epistemológico que o autor apresenta também no capítulo 2, combinando o conceito luxemburguiano com as melhores contribuições dos novos estudos globais do trabalho, da geografia do trabalho, da nova história social e das teorias dos movimentos sociais. Trata-se de entender essas dinâmicas organizativas e espaciais a partir de uma série de aspectos: as interações entre organizações formais (entre as quais figuram os sindicatos, mas não apenas) e laços informais (nos locais de trabalho e também fora deles, a partir de etnia, família, origem regional...); as dinâmicas de formalização e instrumentalização dos laços informais; as conexões entre métodos de atuação pacíficos e violentos; e as interações entre pautas e identificações oriundas dos locais de trabalho e aquelas que transcendem os locais de trabalho, ecoando o reconhecimento de que diversos fatores não classistas intervêm também nos esforços organizativos dos trabalhadores. Todos esses aspectos são atravessados pelas dinâmicas espaciais de nível local, regional, nacional e internacional em que cada processo se situa, sobretudo porque os movimentos grevistas são influenciados por tradições espacializadas de luta.

Para que este modelo se transforme em uma produtiva fonte de inspiração analítica é necessário agregarmos a abordagem etnográfica. Apenas o olhar cuidadoso informado por essa matriz de questões é capaz de captar a riqueza dos processos de agitação trabalhista, em especial, aqueles cujos organizadores não deixaram rastros documentais. Tanto a condenação quanto a romantização da "espontaneidade" das "greves selvagens" é substituída, na obra de Nowak, pelo seu enquadramento científico. Assim, Nowak debruçou-se sobre a atual onda de agitações trabalhistas no Sul global, manifesta em um agudo aumento no número de greves em diversos países periféricos e semiperiféricos, sobretudo entre 2010 e 2014. 
Embora coetâneos às ondas de protestos sociais verificadas no período, os processos de agitação trabalhista receberam menor atenção midiática e acadêmica. Nowak contribui para preencher essa lacuna sobretudo através de um estudo etnográfico sobre a onda de greves na indústria automobilística indiana (capítulo 4) e na indústria da construção civil brasileira (capítulo 5). Nos dois casos, trata-se de "greves de massa de combate dirigidas pelos trabalhadores", apesar de envolvimentos variáveis de sindicatos em cada caso. Os estudos etnográficos conduzidos por Nowak cobrem especificamente as greves na fábrica de Manesar da Maruti Suzuki em 2011 e 2012; a greve na fábrica de Chakan da Bajaj Auto em 2013; greves em Pecém (CE) na construção de uma usina termoelétrica em 2011 e na construção de uma aciaria em 2013; e as greves na construção da usina hidroelétrica de Belo Monte (PA) em 2012.

Em todos esses casos, as greves alcançaram grande repercussão midiática e política, influenciaram outras greves tanto no setor como na região, enfrentaram a repressão policial e criaram novas organizações para as quais a atuação dos sindicatos foi apenas um dos fatores, raramente o mais importante, ao lado de diversos laços informais, identidades regionais ou nacionais, movimentos sociais e partidos locais. Devido a essa diversidade de variáveis, cada estudo de caso consiste em uma narrativa peculiar, com resultados muito distintos, como o autor reconhece, que dificultam postular uma tendência geral. No conjunto, todos envolveram importantes saldos organizativos, embora por caminhos tortuosos: alguns produziram alianças mais profundas e duráveis com outros movimentos sociais (Maruti Suzuki e Belo Monte), levando mesmo à criação de novas organizações de base territorial focadas na mobilização de trabalhadores informais (Maruti Suzuki); outros se aproximaram mais de um modelo corporativista de sindicalismo, embora criando novas formas de organização no local de trabalho a partir dos laços informais dos trabalhadores precários.

Mas apesar de importantes saldos organizativos desses processos, o autor reconhece ao mesmo tempo que, comparado com outras ondas grevistas globais, essa não foi acompanhada por intensidade similar em termos de criação de novos sindicatos. Ademais, as ondas grevistas estudadas não foram capazes de produzir novas coalizões políticas nacionais que pudessem enfrentar as políticas neoliberais e financeirizadas dos governos. Tanto na Índia quanto no Brasil, essas greves antecederam ou foram acompanhadas por grandes protestos de rua cujo destino geral evoluiu rumo ao fortalecimento de governos conservadores e autoritários, em uma clara dinâmica política do tipo "reforma-contrarreforma".

Esse aspecto anticlimático da atual onda grevista é o grande enigma que a leitura de Nowak apresenta, e para o qual ainda não há uma resposta satisfatória. O autor observa que a indisposição das forças hegemônicas de esquerda em apoiar as greves e formular uma proposta coerente de renovação social que pudesse ter conectado os anseios inicialmente progressivos das passeatas de rua com as agitações trabalhistas deixou aberto o espaço para que movimentos autoritários tomassem conta da cena política, cooptando o sentido dos atos 
e "isolando" as greves. Ou seja, ao contrário do que ocorreu no Brasil durante o ciclo grevista dos anos 1970 e 1980, os novos ativistas sindicais não foram capazes de propor um grande projeto de esquerda alternativo para as forças progressistas. Por outro lado, na Índia dos anos 1970, o destino político do ciclo grevista foi mais parecido com o atual contexto, revelando que o cenário presente não é desprovido de precedentes. Compreender esses desfechos é, antes de mais nada, uma questão para ser tratada pela sociologia política. No caso brasileiro, trata-se de explicar como um conjunto de ativistas ultraconservadores e neoliberais, há uma década, completamente marginais na cena política nacional, conseguiu em poucos anos monopolizar o espaço de oposição ao PT.

Entender como os trabalhadores precários, sobretudo aqueles envolvidos nas greves de massas, lidaram com as transformações políticas nacionais em escala global é parte de uma ampla e urgente agenda investigativa. Temos procurado impulsionar tal agenda partindo da hipótese segundo a qual, desde a crise de 2008, a classe trabalhadora experimenta em escala global um período marcado pelo "refazer-se" de identidades coletivas cuja característica mais saliente consiste na sobreposição de agitações que tanto defendem pactos sociais e direitos trabalhistas conquistados no passado pelos sindicatos quanto buscam criar novas modalidades de ação e de representação dos interesses coletivos por meio da organização de trabalhadores pobres e precários. Trata-se de um esforço internacional que, ao mesmo tempo, deve ser resolutamente enraizado em cada cenário político nacional. Nessa direção, a abordagem etnográfica comparativa internacional é insubstituível. E o livro de Jörg Nowak aponta a direção teórica, metodológica e política para onde devem ir nossos melhores esforços investigativos. 